\title{
10 MW, L-Band Klystron for Accelerators
}

\author{
Phase I Final Report
}

Grant Number DE-SC0001499

Calabazas Creek Research, Inc.

690 Port Drive

San Mateo, CA 94404

(650) 312-9575, Fax: (650) 312-9536

RLI@CalCreek.com

Principal Investigator: Dr. Michael Read

Topic Number: 37

Subtopic Number: b

May 21, 2010 


\section{Introduction}

Calabazas Creek Research Inc. (CCR) completed Phase I the development of a $10 \mathrm{MW}, 1.3 \mathrm{GHz}$, annular beam klystron (ABK) for driving advanced accelerators, such as the International Linear Collider (ILC). Through detailed simulations in Phase I, CCR produced a design that meets all of the requirements for ILC [1].

The ABK uses an annular beam to minimize space charge depression and the impedance. This allows the relatively low voltage of $120 \mathrm{kV}$ specified for the International Linear Collider (ILC). Like the sheet beam klystron (SBK), the ABK uses a thin beam located close to the drift tube walls; however, it operates with lower risk, single mode cavities. In addition, it is azimuthally symmetric, dramatically reducing design and fabrication costs. It provides the same operating characteristics as a multi-beam klystron (MBK), but is far simpler and will be easier and less expensive to fabricate.

A summary of the ABK operating parameters is given in Table 1. All of these parameters meet or exceed the goals of the Phase I program, and there is high confidence that a Phase II device will meet the ILC requirements. A preliminary solid model is shown in Figure 1.

Because of its azimuthal symmetry and single

Table 1. Calculated operating parameters of the proposed ABK.

\begin{tabular}{|l|l|}
\hline Parameter & $\begin{array}{l}\text { Calculated } \\
\text { Value }\end{array}$ \\
\hline Frequency & $1.3 \mathrm{GHz}$ \\
\hline Power & $10.7 \mathrm{MW}$ \\
\hline Efficiency & $64 \%$ \\
\hline Voltage & $120 \mathrm{kV}$ \\
\hline Pulse width & $1.5 \mathrm{~ms}$ \\
\hline Pulse repetition rate & $10 \mathrm{~Hz}$ \\
\hline Cathode loading & $1.9 \mathrm{~A} / \mathrm{cm}^{2}$ \\
\hline
\end{tabular}

beam line, the $\mathrm{ABK}$ is much simpler than an MBK. This is illustrated in Figure 2 - Figure 4.

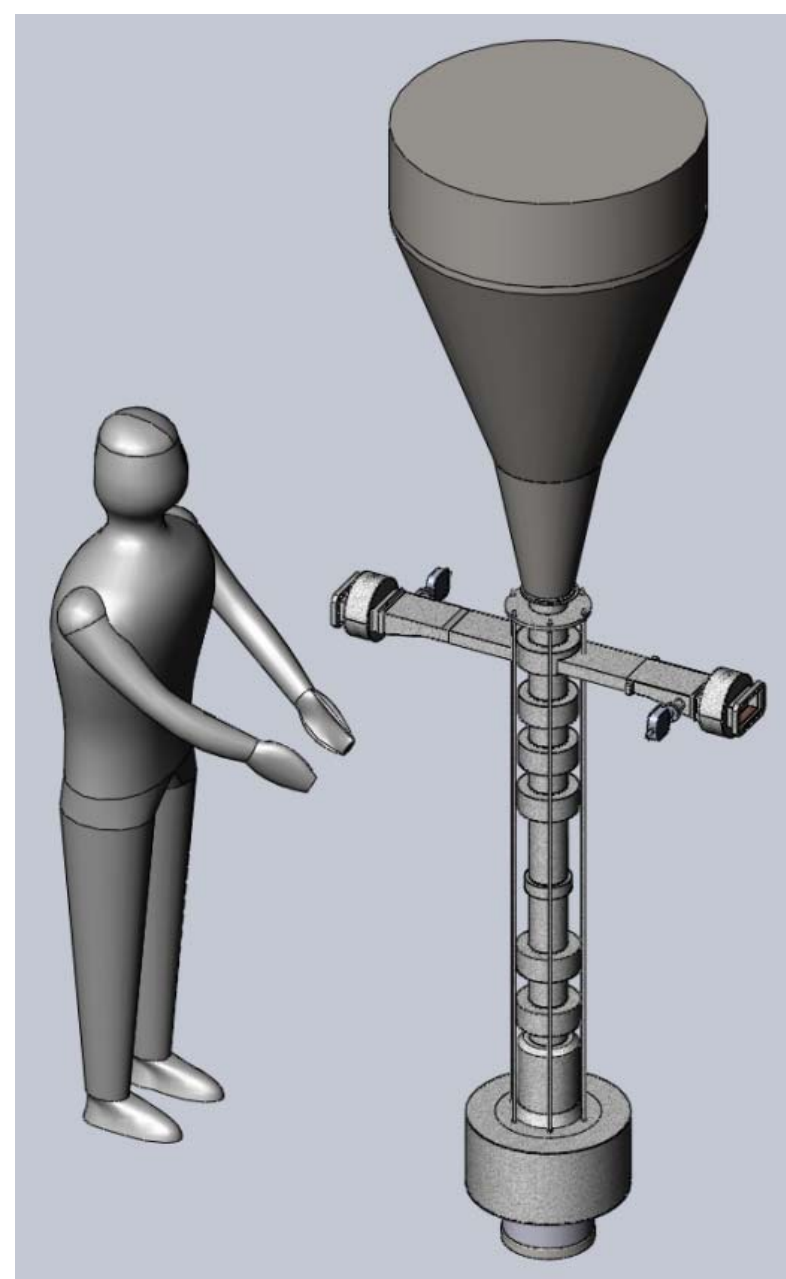

Figure 1. Solid model of the ABK. 


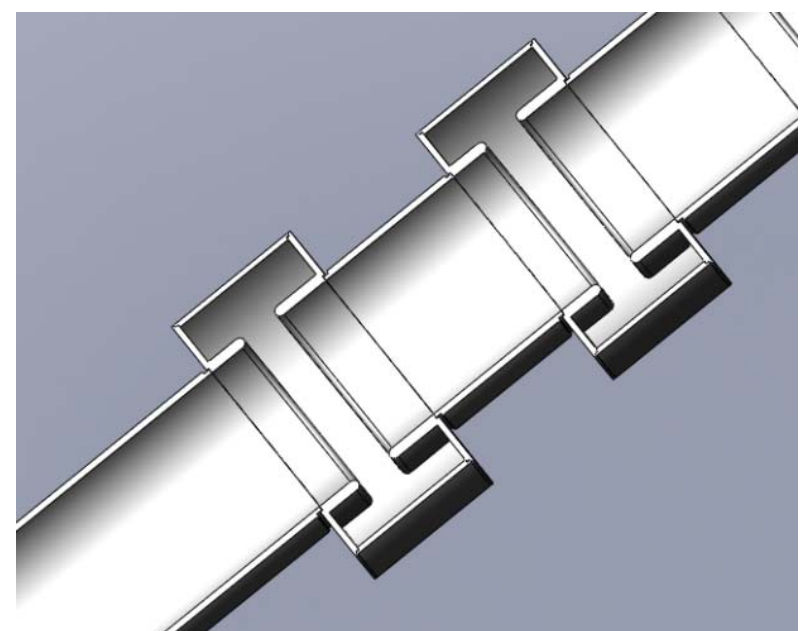

Figure 2. Annular beam klystron electron gun and circuit

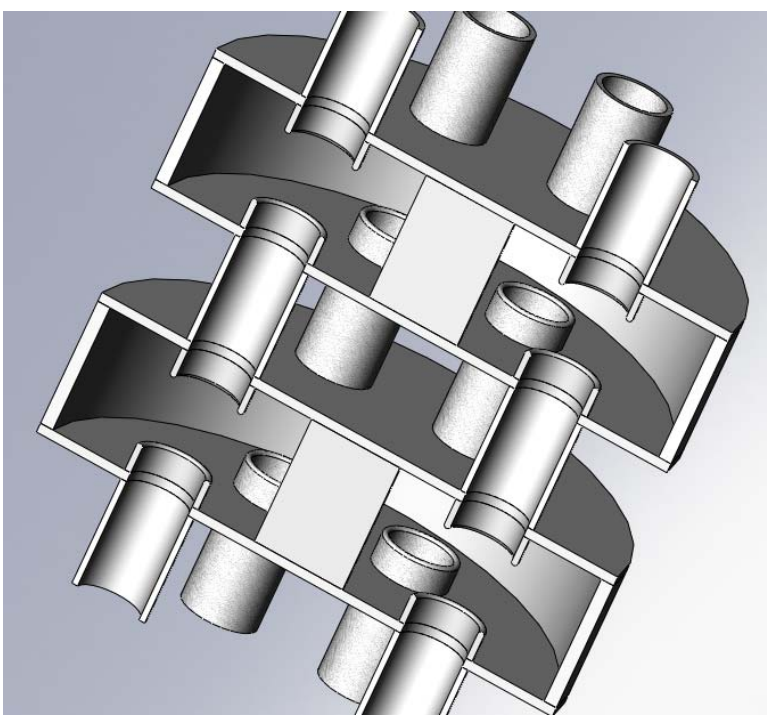

Figure 3. Circuit, gun and magnet of the Toshiba LBand multi-beam klystron, showing the multiple beam lines and complex cavities.
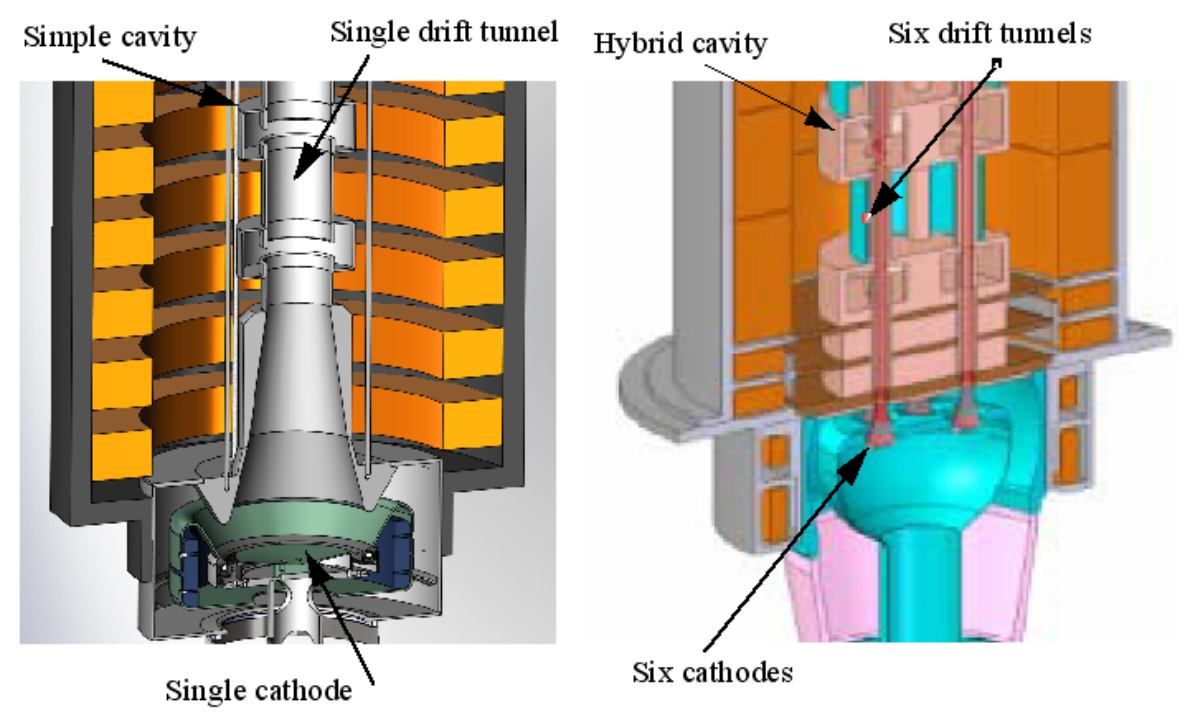

Figure 4. Comparison of electron gun and cavities in the annular beam klystron (left) and the Toshiba multiple beam klystron (right).

This simplicity will result in significantly lower fabrication costs and potentially higher reliability. It is estimated that the cost of the ABK will be approximately $70 \%$ of an MBK [1]. The ILC will require approximately 600 klystrons. Using klystron costs estimated by Stanford Linear Accelerator Center, this results in a cost savings for the klystrons of approximately $\$ 30$ million. The simplified design and cost reduction, combined with competitive performance, make the ABK a superior choice for the ILC. 


\section{Anticipated Public Benefits}

The ABK is targeted for advanced accelerators and colliders for high energy physics research. Accelerators are also used for diagnosing and treating cancer and other diseases. The proposed program would result in less expensive RF sources and power supply systems, thus reducing the cost for many applications. Two other devices, the multi-beam klystron and the sheet beam klystron, also operate at low voltage and are under development at various institutions. The ABK is significantly simpler and less expensive than the multi-beam klystron. Because it uses fundamental mode cavities and is cylindrically symmetric, the ABK is also much easier to design and fabricate than the sheet beam klystron.

The voltage reduction would also be an advantage in the radar community. The lower voltage reduces size, increases efficiency, and provides larger bandwidth. Microsecond-long pulse, high peak power sources are of interest to the Department of Defense (DoD) for high power microwave weapons and effects testing. The ABK, as tested in the proposed program, will be an important step in the development of a new, high power RF source. 


\section{Degree to which Phase I has Demonstrated Technical Feasibility}

All technical objectives for the Phase I program were achieved. Consequently, an L-Band annular beam klystron producing $10 \mathrm{MW}$ of pulsed RF power is clearly feasible. Details of the Phase I program are presented below.

\section{Phase I Technical Objectives}

The Phase I objective was to demonstrate feasibility of a $10 \mathrm{MW}$, annular beam klystron with parameters appropriate for advanced accelerators such as the International Linear Collider (ILC). The design goals are given in Table 2 .

Table 2. Design goals for the proposed ABK

\begin{tabular}{|l|l|l|}
\hline Parameter & Goal & Achieved \\
\hline Frequency & $1.3 \mathrm{GHz}$ & $1.3 \mathrm{GHz}$ \\
\hline RF Output Power & $10 \mathrm{MW}$ & $10.8 \mathrm{MW}$ \\
\hline Efficiency & $\geq 60 \%$ & $64 \%$ \\
\hline Voltage & $\leq 120 \mathrm{kV}$ & $120 \mathrm{kV}$ \\
\hline Pulse width & $1.5 \mathrm{~ms}$ & $1.5 \mathrm{~ms}$ \\
\hline Pulse repetition rate & $10 \mathrm{~Hz}$ & $10 \mathrm{~Hz}$ \\
\hline Cathode loading & $\leq 2 \mathrm{~A} / \mathrm{cm}^{2}$ & $1.9 \mathrm{~A} / \mathrm{cm}^{2}$ \\
\hline
\end{tabular}

The program demonstrated feasibility by creating designs of the major components of the klystron, including the following:

(1) Circuit

(2) Electron gun and collector

(3) Input and output windows

(4) Magnetic circuit

All of the goals were achieved for the Phase I program, and there is a high level of confidence in the design. Multiple analysis codes were used to confirm the design parameters. The ABK appears to be a superior candidate as a RF source for the ILC.

An illustrative solid model of the tube is shown in

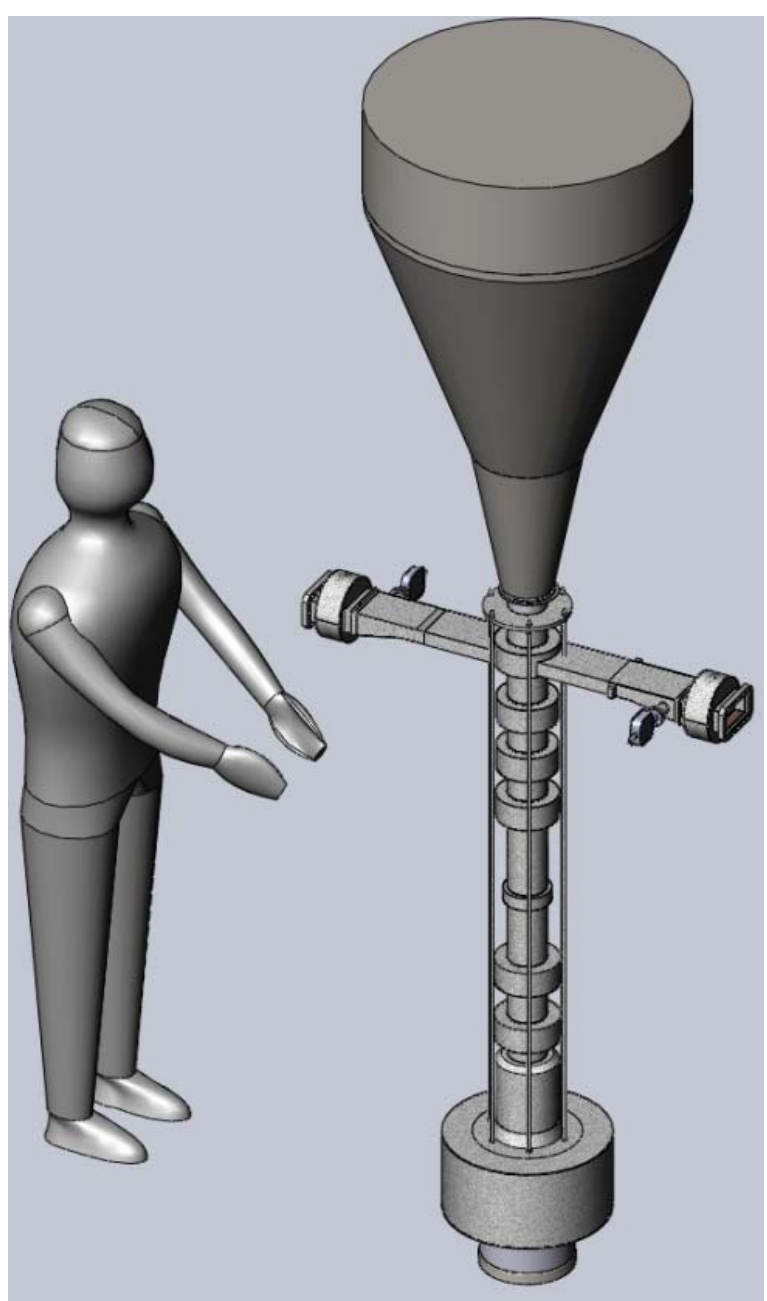

Figure 5. Solid model of the $10 \mathrm{MW} 1.3 \mathrm{GHz}$ ABK. Figure 5.

Details of the results of the individual tasks are discussed below. 


\section{Task (1): Design of the RF Circuit}

The RF circuit was designed using the large signal codes KLSC [2] and TESLA [3] and the particle in cell (PIC) code MAGIC2D/3D [4]. KLSC is a $2 \frac{1}{2} \mathrm{D}$, large signal, simulation code that includes a self-consistent calculation of the so-called "edge space charge" and uses cavity RF fields from SUPERFISH to model beam loading. It can model both conventional and annular beam configurations. KLSC has been compared to experimental data for a SLAC $150 \mathrm{MW}$, Sband klystron and a SLAC $60 \mathrm{MW}$, X-band klystron. Agreement was within $1 \%$ for efficiency and within $1.5 \mathrm{~dB}$ in saturated gain. KLSC was the primary computational code for the circuit design in this program. KLSC results were confirmed using the codes TESLA and MAGIC.

The design considered the following:

- Reflected electrons,

- Field magnitudes in cavity gaps,

- Location and power density of any intercepted beam,

- Stability against monotron oscillations,

- Heating during the $1.5 \mathrm{~ms}$ pulse.

\section{KLSC Design}

Two designs with different drift tube diameters were investigated in detail. Both designs used seven cavities, including one at the second harmonic. The $8.8 \mathrm{~cm}$ diameter drift tube resulted in excessive RF leakage between cavities, and there was concern that this would reduce the efficiency. The drift tube diameter was reduced to $8 \mathrm{~cm}$, resulting in a higher efficiency. Simulations

Table 3. Parameters of the RF Circuit

\begin{tabular}{|l|l|}
\hline Center Frequency & $1.3 \mathrm{GHz}$ \\
\hline RF Power Out & $10.8 \mathrm{MW}$ \\
\hline Efficiency & $64.2 \%$ \\
\hline Pulse width & $1.5 \mathrm{~ms}$ \\
\hline Beam Perveance & 3.37 micropervs. \\
\hline Beam Voltage & $120 \mathrm{kV}$ \\
\hline Beam Current & $140 \mathrm{~A}$ \\
\hline RF Power In & $140 \mathrm{~W}$ \\
\hline Saturated Gain & $49 \mathrm{~dB}$ \\
\hline Drift tube radius & $4.0 \mathrm{~cm}$. \\
\hline Outer Beam Radius & $3.6 \mathrm{~cm}$ \\
\hline Inner Beam Radius & $3.2 \mathrm{~cm}$ \\
\hline Beam Current Density & $16.4 \mathrm{~A} / \mathrm{cm}^{2}$ \\
\hline Magnetic Focusing Field & $2 \mathrm{kG}$ \\
\hline Number of Cavities & 7 \\
\hline $\begin{array}{l}\text { Circuit Length } \\
\text { (Gap 1 - Gap 7) }\end{array}$ & $0.93 \mathrm{Meters}$ \\
\hline
\end{tabular}
with TESLA and MAGIC confirmed the results.

The results for the $8 \mathrm{~cm}$ diameter drift tube design are summarized in Table 3 .

A section of the interaction circuit, shown schematically in Figure 6, consists of two cavities followed by a second harmonic cavity, three penultimate cavities and an output cavity. The klystron uses conventional, double reentrant cavities operating in the $\mathrm{TM}_{01}$ fundamental mode. Figure 7 shows a cross section of the output cavity as modeled in SUPERFISH. The output cavity is loaded by two inductive irises $180^{\circ}$ apart. This will require an elliptical cavity to equalize the orthogonal electric fields. The maximum electric field in the output cavity is 154 $\mathrm{kV} / \mathrm{cm}$ which is less than $1 / 2$ of the Kilpatrick limit of $321 \mathrm{kV} / \mathrm{cm}$. 


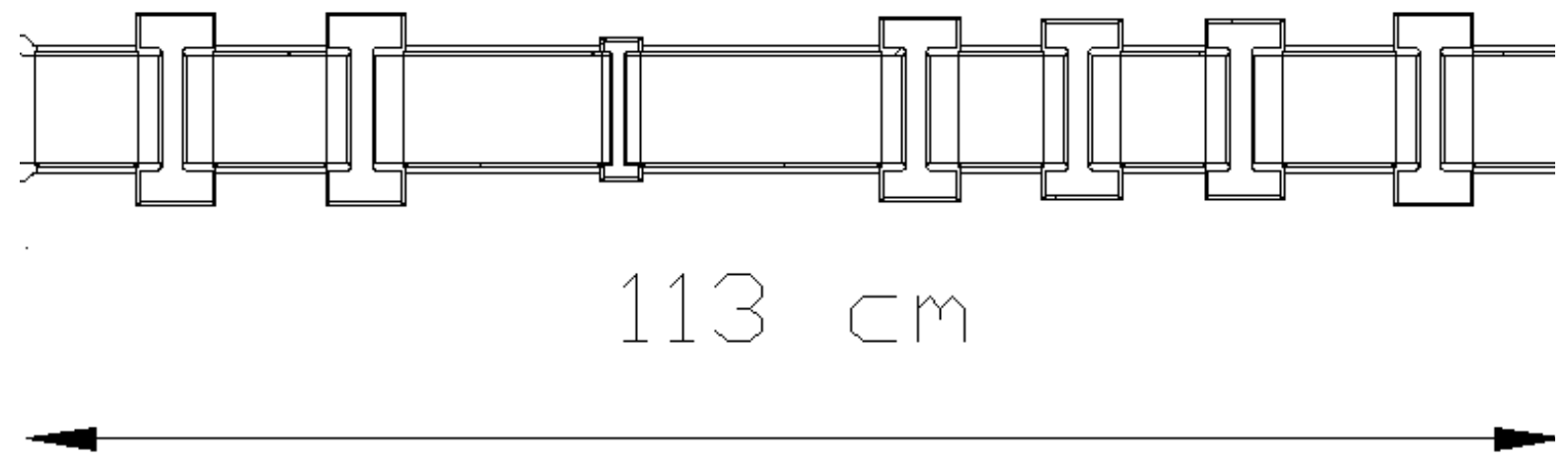

Figure 6. RF circuit. (Input and output couplers not shown.)

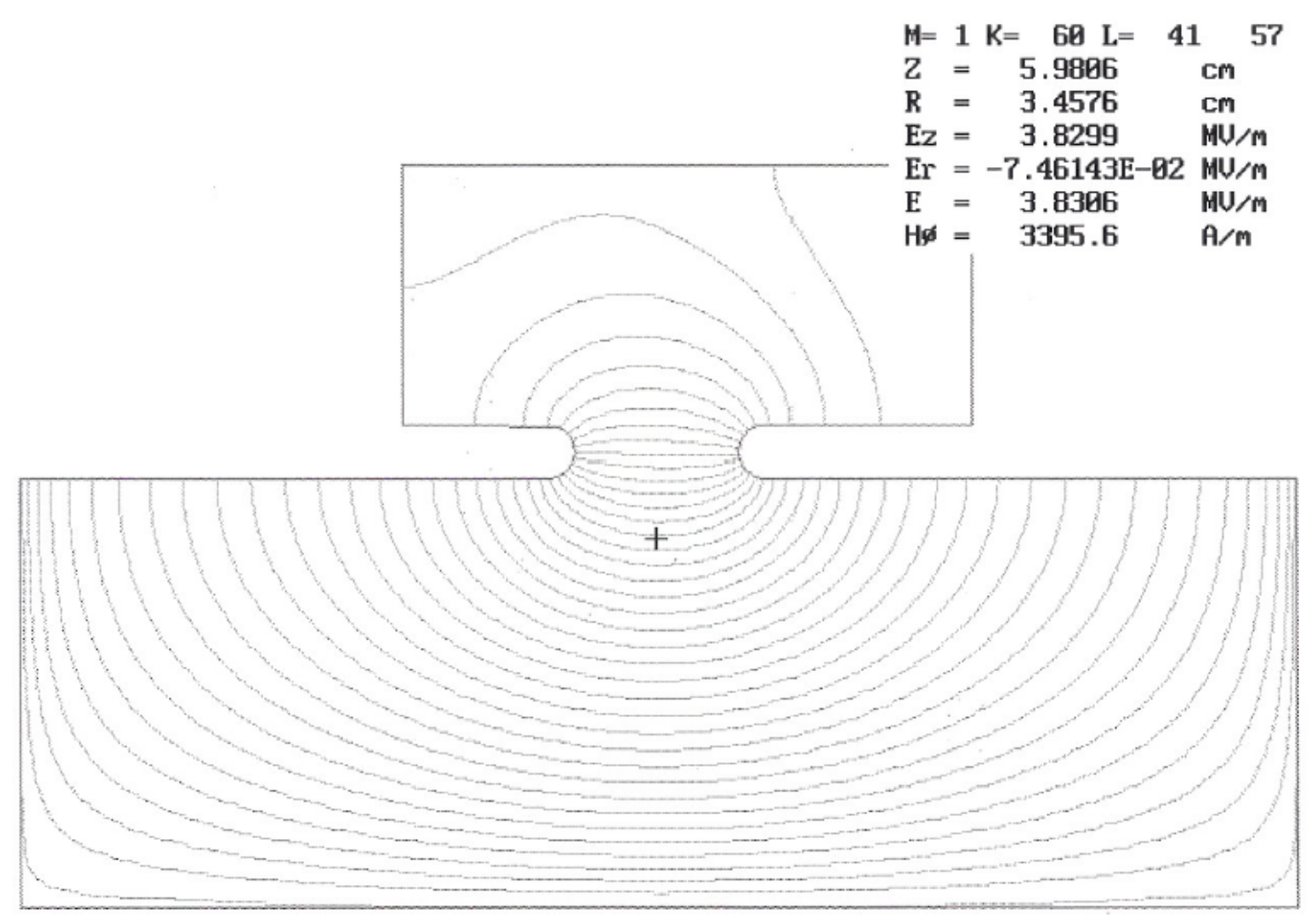

Figure 7. Cross Section of the Double Reentrant Output Cavity Operating in the TM01 Mode 
Figure 8 shows the hollow electron beam consisting of eight deformable rings traversing the seven cavity interaction circuit. The axial positions of the seven cavities are indicated by the marks on the horizontal bottom line. Note the absence of any radial modulation of the electron beam, i.e. the electron beam is well confined and is modulated longitudinally. The change in magnitude for the radial component, $\mathrm{E}_{\mathrm{r}}$ across the annular beam is less than 10 percent, which accounts for the absence of radial modulation. For a conventional solid beam klystron with a $60 \%$ fill factor, the change in magnitude of $E_{r}$ can be as much as ten times greater.

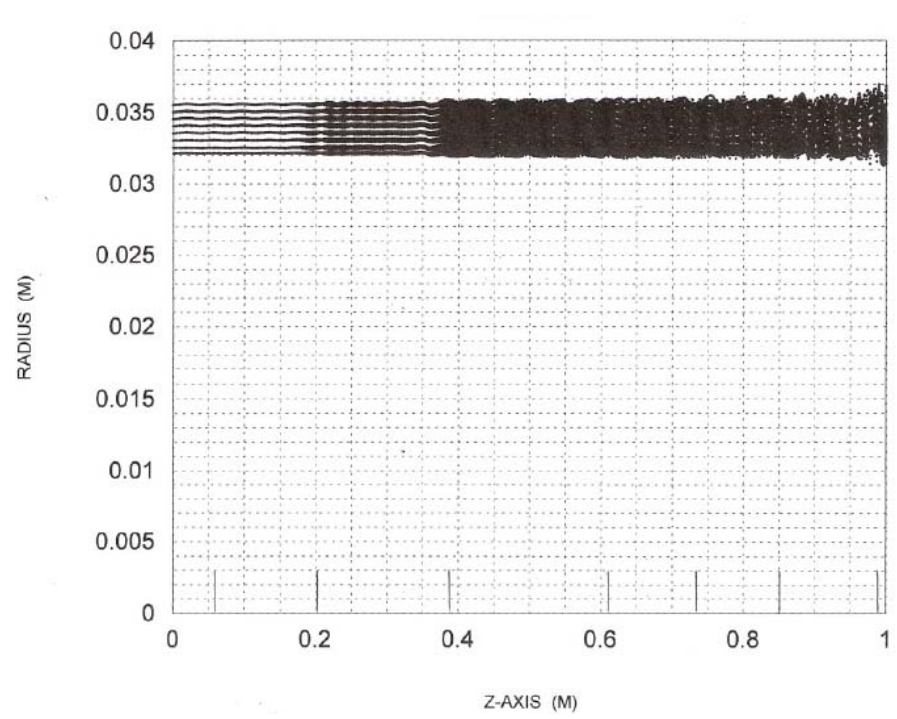

Figure 9 shows Beta, the beam velocity normalized to the speed of light, for the eight ring annular beams. Note the large decrease in Beta at the output cavity. For all simulations, the RF input power was adjusted to achieve saturation without reflecting electrons. This criteria was followed for every iteration of the simulation where the gap to gap spacing, cavity frequency and drift tube radius were varied individually. The radial Beta is shown in Figure 10. Note the difference in magnitude and large spread in magnitude for the axial Beta. This difference supports the small radial modulation of the annular electron beam.

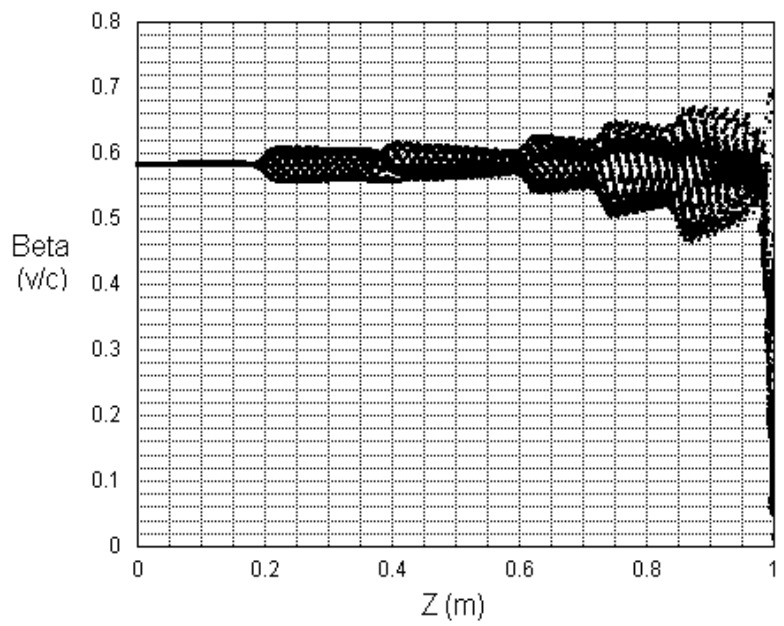

Figure 9. Axial Beta versus Axial Distance for the Eight Ring Annular Beam.

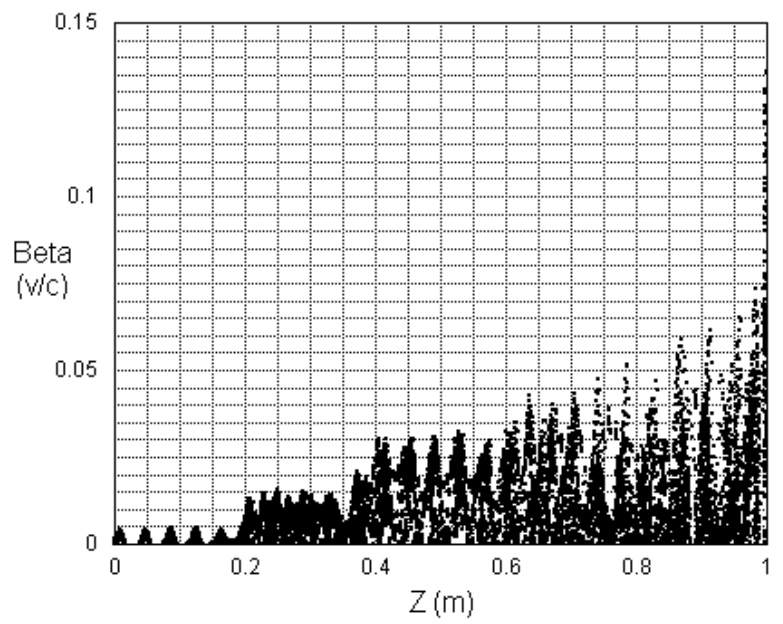

Figure 10. Radial beta versus axial distance for the eight ring annular beam. 
The efficiency as a function of axial magnetic field is shown in Figure 11. The various interdependent parameters of the circuit were varied to optimize the efficiency for each variation in axial magnetic field. The magnetic field was varied with both positive and negative taper at the output for each value of axial magnetic field. Maximum efficiency was achieved with a constant field of 2000 Gauss.

The RF output power as a function of RF input power is shown in Figure 12. Note that this is a typical "RF compression curve," quite similar to that exhibited by a solid beam klystron. The maximum RF output power is $10.8 \mathrm{MW}$.

The ohmic loss in the output cavity, as calculated by SUPERFISH, is $29 \mathrm{~kW}$. The maximum power density is approximately $50 \mathrm{~W} / \mathrm{cm}^{2}$. This will produce less than $1^{\circ} \mathrm{C}$ rise during the $1.5 \mathrm{~ms}$ pulse. The average ohmic power will be 435 $\mathrm{W}$, which is easily cooled with water.

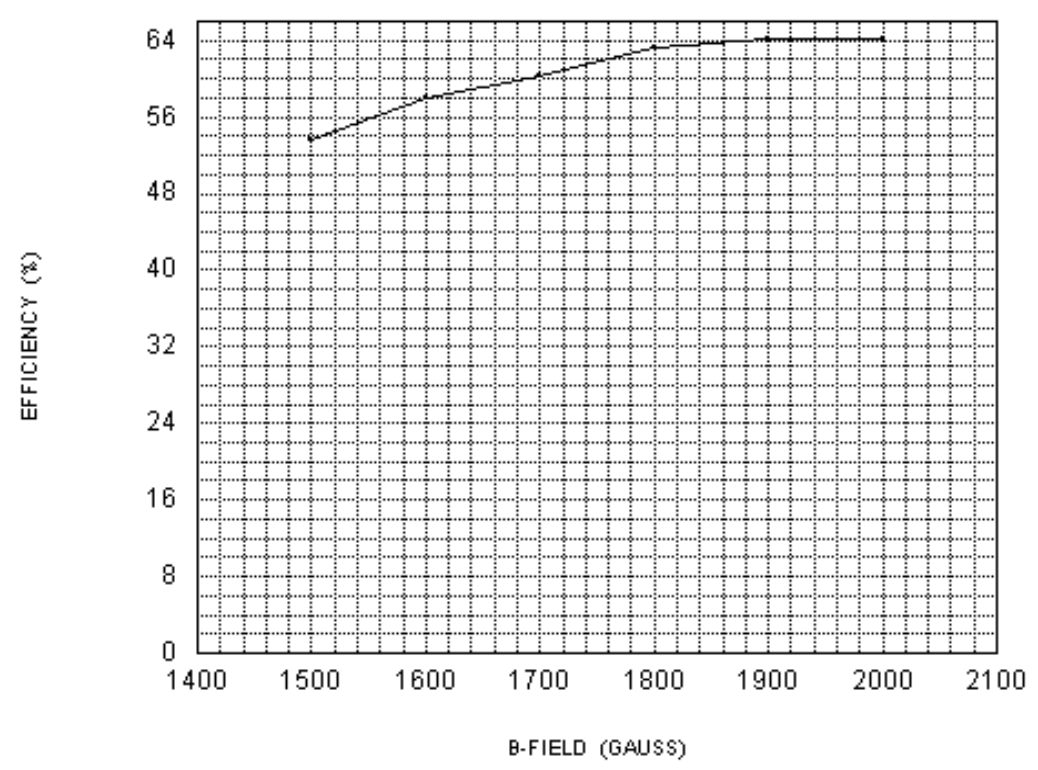

Figure 11. Efficiency versus Axial Magnetic Field

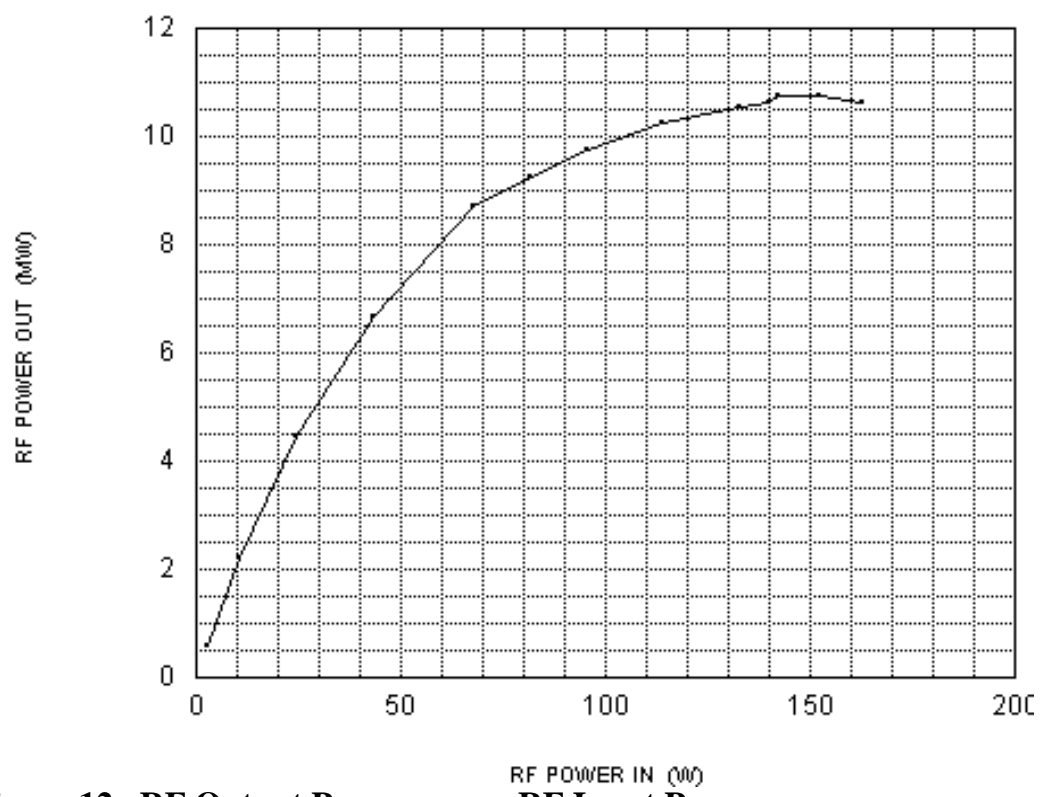

Figure 12. RF Output Power versus RF Input Power 


\section{TESLA results}

TESLA is an advanced circuit simulation code for klystrons and similar RF devices. It uses the telegrapher's equations, calculating the beam-wave interaction on the time scale of the change of the RF fields. The fields in the drift tube are calculated self-consistently, with the fields at the cavity gaps. More details of the code can be found in reference [3]. TESLA is, in principle, well suited to modeling annular beam devices. CCR personnel consulted extensively with the code developers [5] to

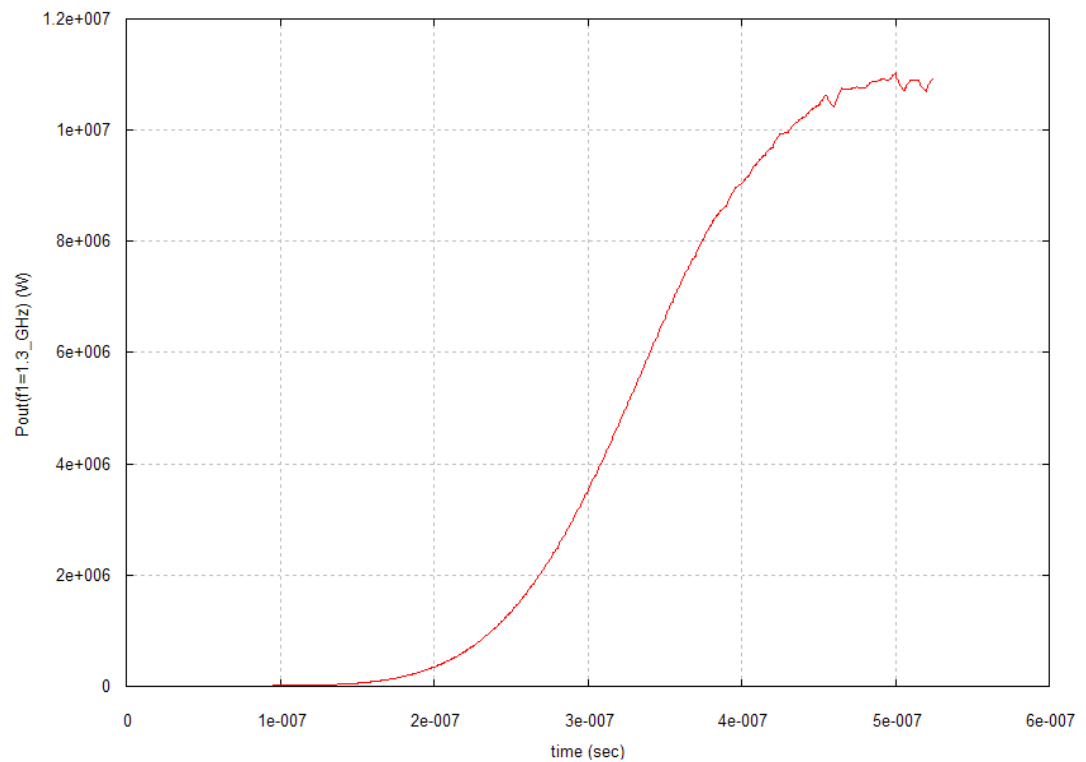

Figure 13. Output power as a function of time from the TESLA simulation. insure accurate simulations. The only issue concerned the relatively small diameter of the Larmor orbits due to the high magnetic field. This was resolved by decreasing the computational mesh size.

The TESLA results are shown in Figure 13 through Figure 15. The power as a function of time is shown in Figure 13. The power at saturation is $10.7 \mathrm{MW}$, in very good agreement with the calculation from KLSC (10.8 MW).

The beam from TESLA at saturation is shown in Figure 14, and the electron momenta distribution is shown in Figure 15. Both are in agreement with the results from KLSC.

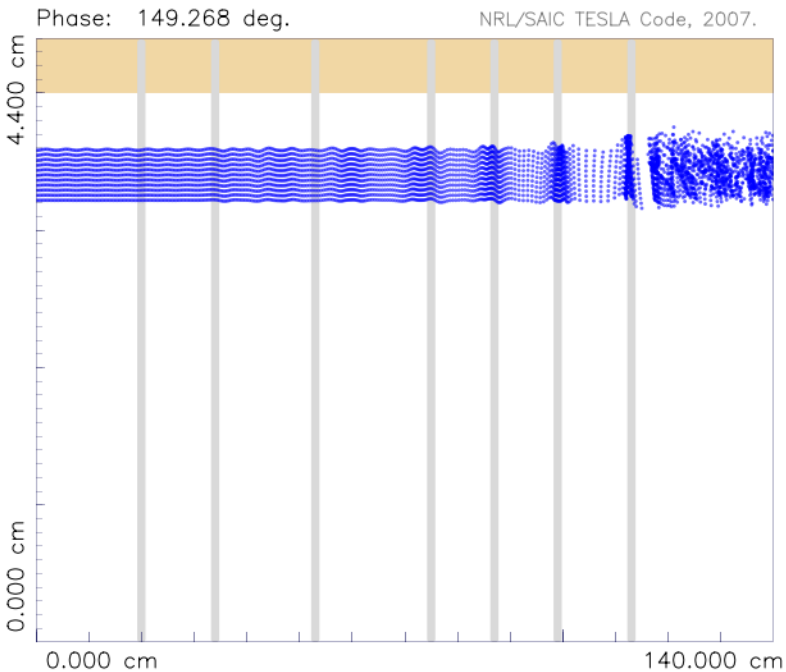

Figure 14. The electron beam at saturation.

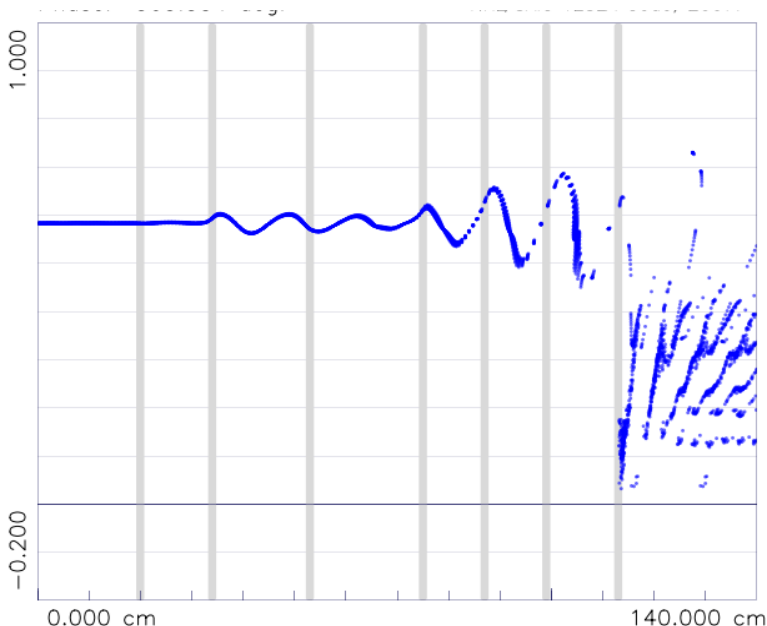

Figure 15. Beta as a function of distance 


\section{Results from MAGIC simulations}

For additional confirmation, the ABK circuit was simulated with MAGIC 2D. The inputs included the geometry of the RF structure, the beam parameters, and the input power and frequency. The RF fields in the cavities and drift region are calculated self consistently in the presence of the beam. Therefore, this is a more realistic simulation than provided by the other codes. Each simulation required five hours, so the code was only used to confirm results from KLSC and TESLA.

The geometry, as shown in Figure 16, is the same as used in KLSC and TESLA. The beam in the last two cavities is shown in Figure 17. As seen in the other simulations, the beam is very well confined radially.

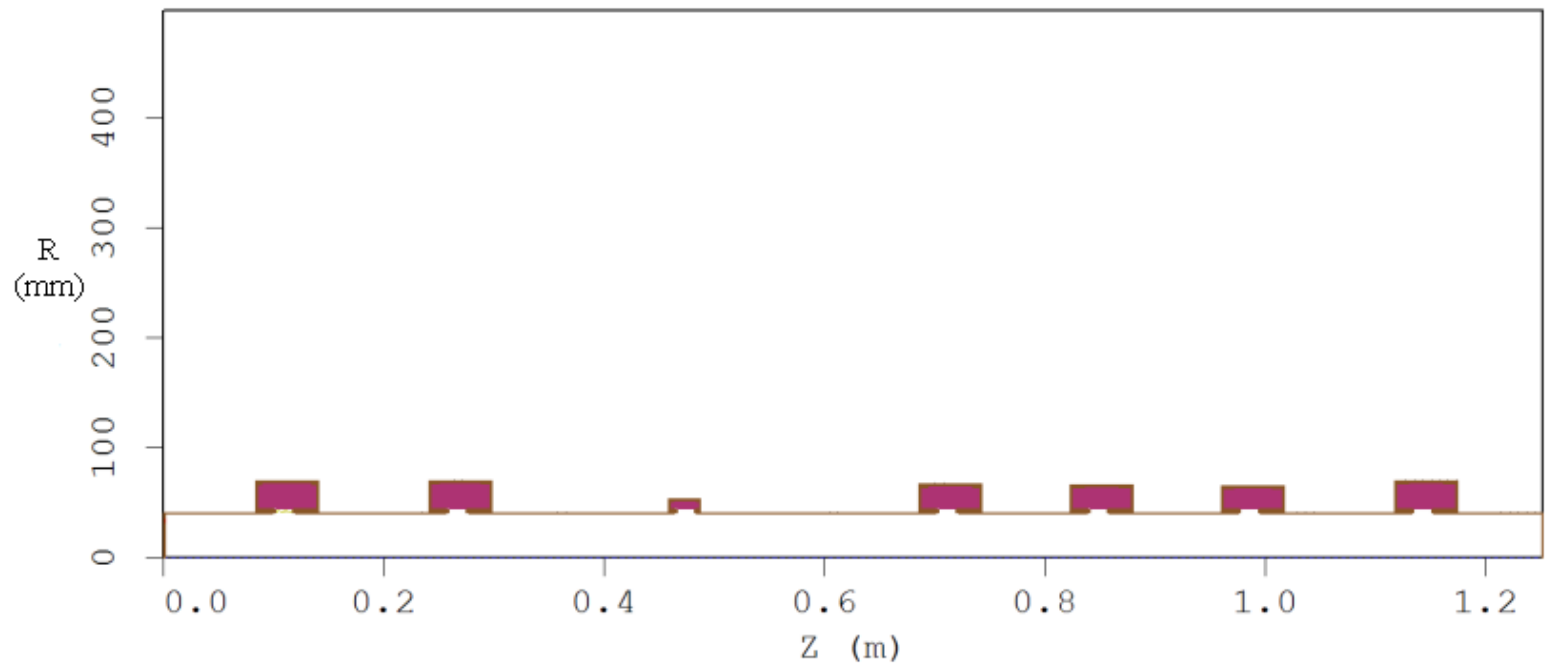

Figure 16. Geometry used in the MAGIC simulations.

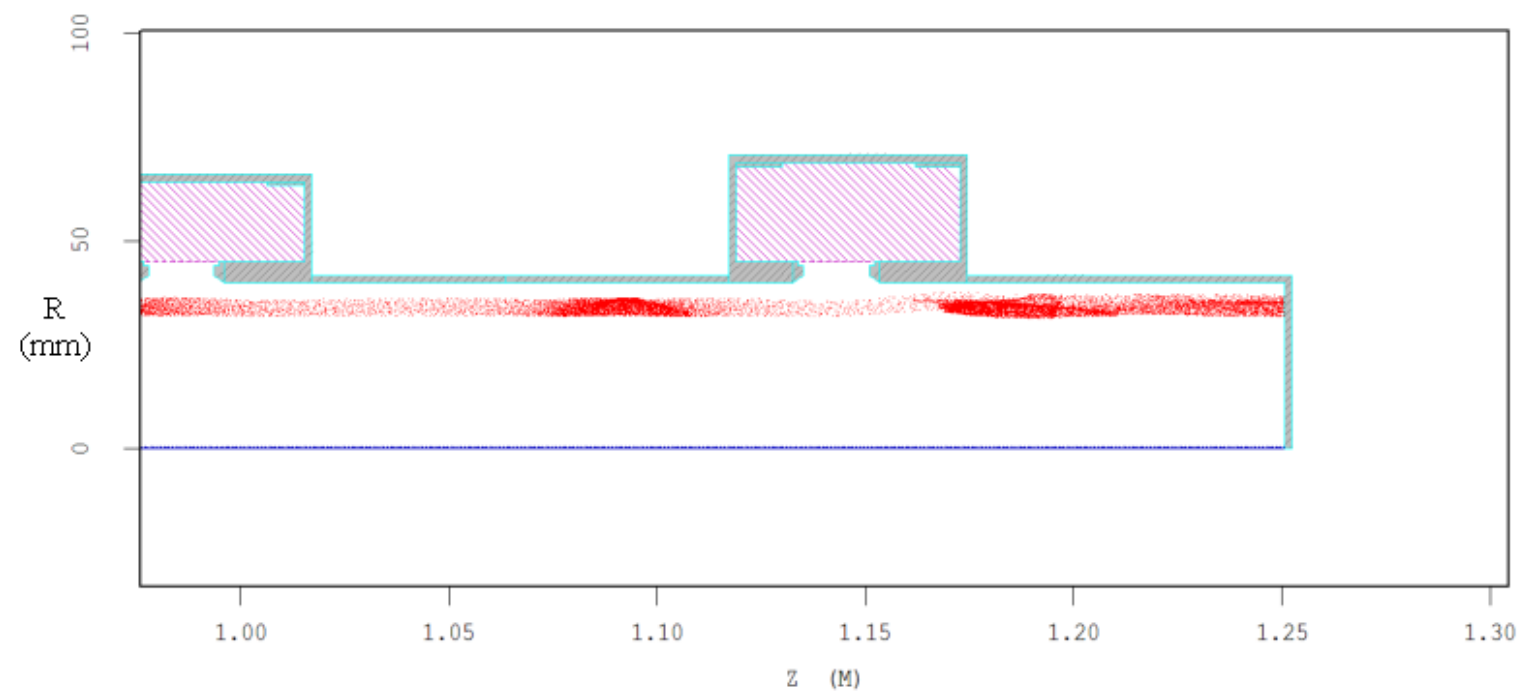

Figure 17. Beam distribution at a single point in time near the output cavity. 
The electron momentum distribution along the tube is shown in Figure 18. This is similar to the plots shown in Figure 9 and Figure 15.

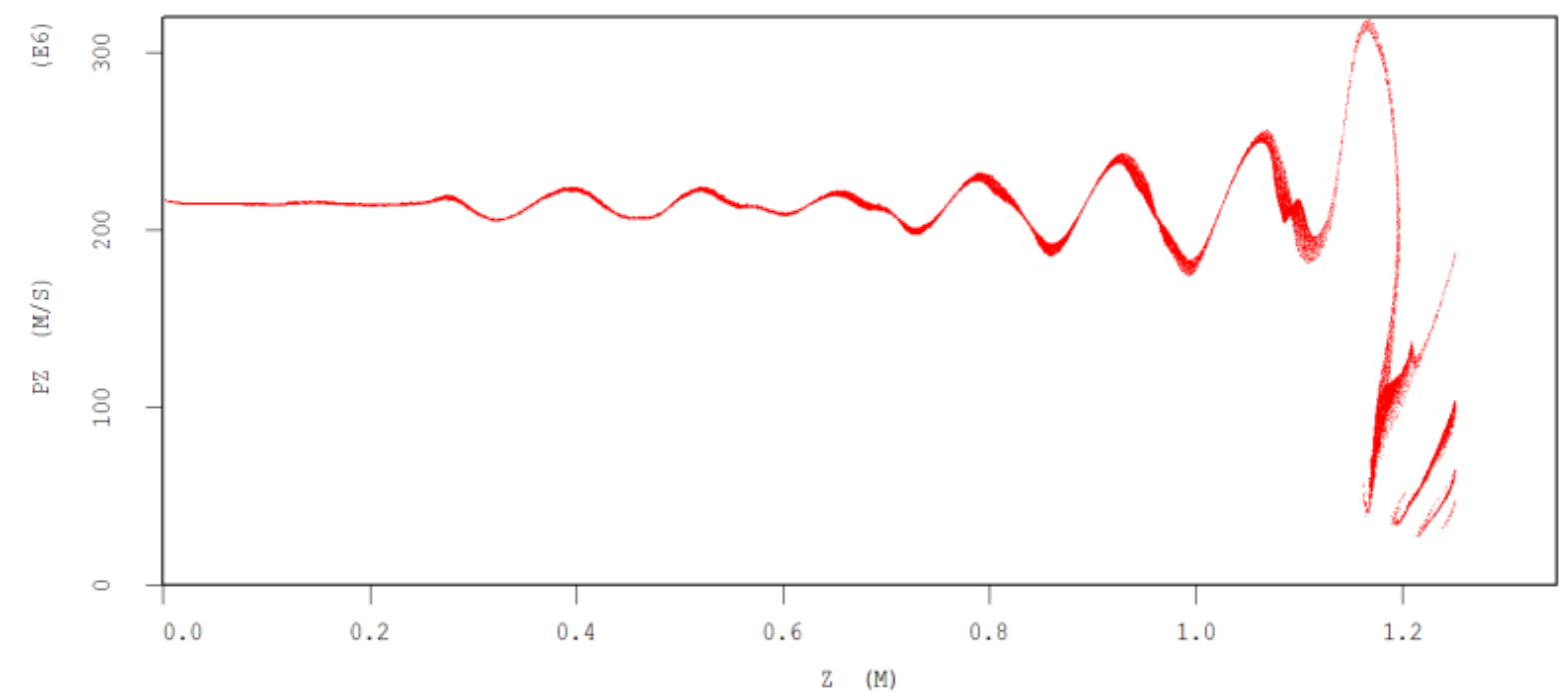

Figure 18. Electron momentum distribution at equilibrium, from the MAGIC simulations.

The output power in time is shown in Figure 19. The power at equilibrium is $10.9 \mathrm{MW}$, in almost exact agreement with the other simulations.

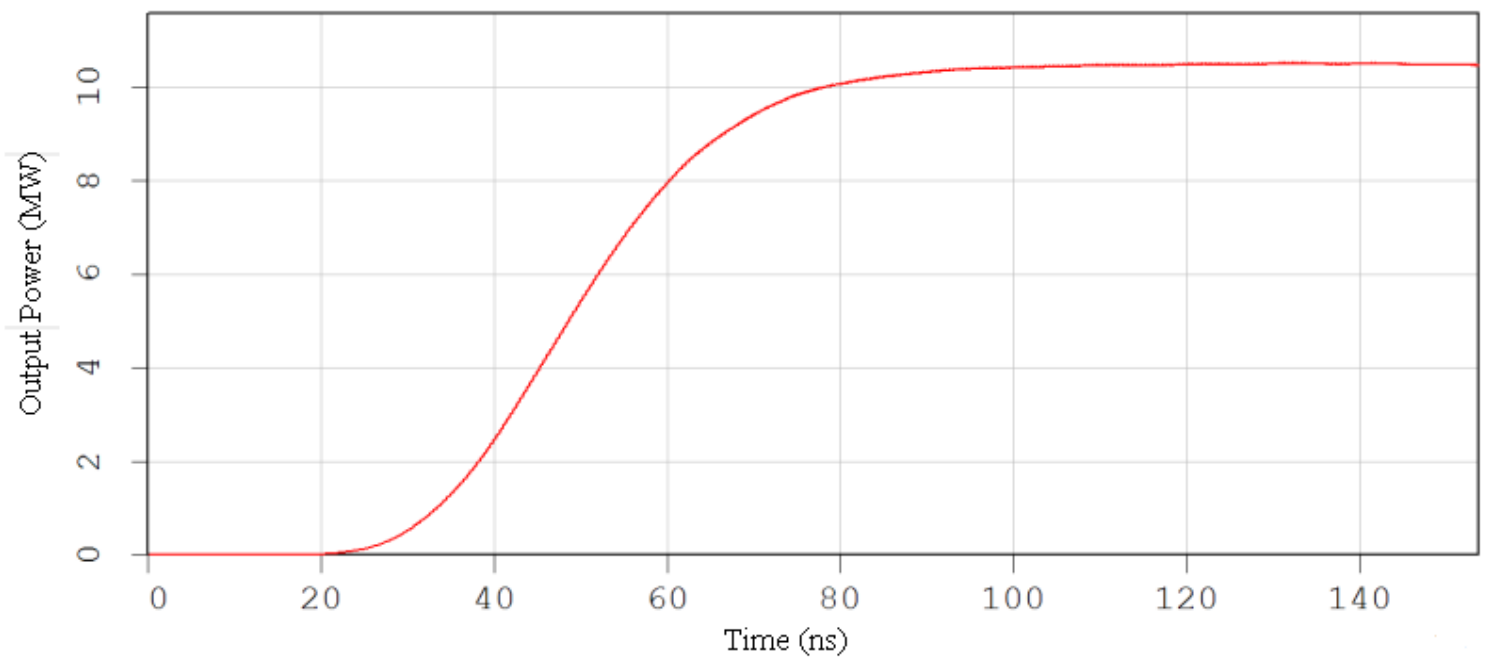

Figure 19. RF output power versus time. The saturated power is $10.5 \mathrm{MW}$. 


\section{Task (2): Electron Gun Design}

Figure 20 shows a simulation of the electron gun using the 2D code TRAK. Design and performance parameters are shown in Table 4. The cathode loading is $1.9 \mathrm{~A} / \mathrm{cm}^{2}$, below the ILC specification of $2 \mathrm{~A} / \mathrm{cm}^{2}$.

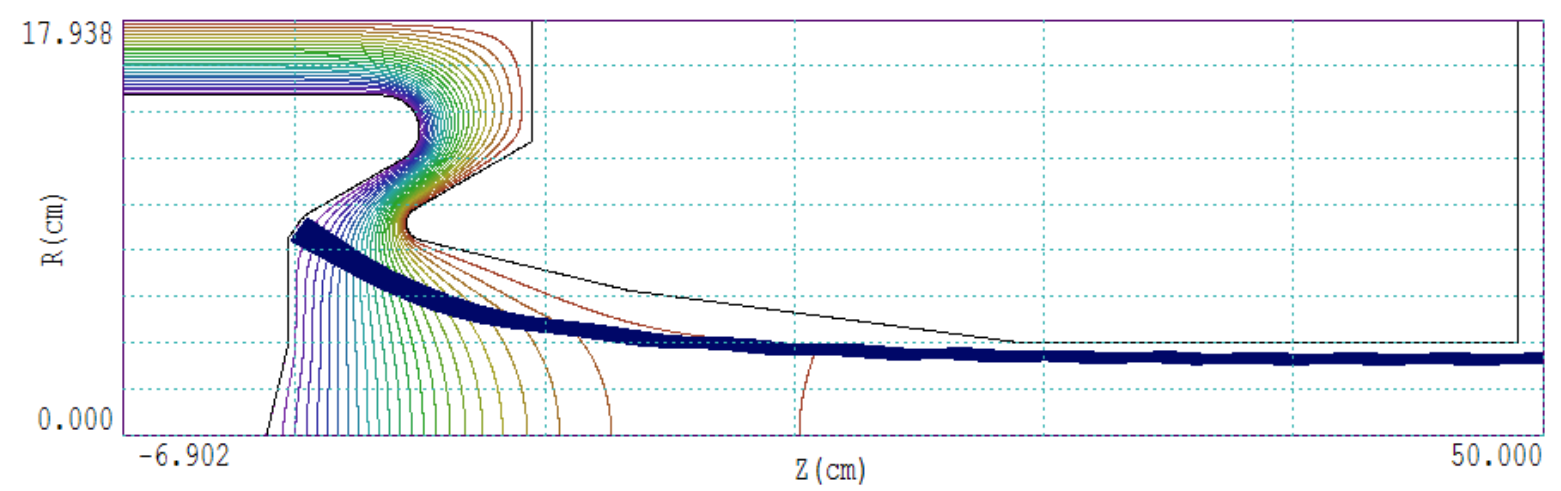

Figure 20. Final gun design, showing trajectories and potential contours.

The diode and support geometry is shown in Figure 21. The peak field on the focus electrode is $64 \mathrm{kV} / \mathrm{cm}$. The maximum allowable field is generally accepted as [6]

$$
E=\frac{100 \tau^{-0.34}}{V}
$$

where $E$ is the field in $\mathrm{kV} / \mathrm{mm}, V$ is the anode-cathode voltage in $\mathrm{kV}$ and $\tau$ is the time in seconds. For the ABK's parameters, the maximum $E$ is $7.6 \mathrm{kV} / \mathrm{mm}$, or $76 \mathrm{kV} / \mathrm{cm}$.
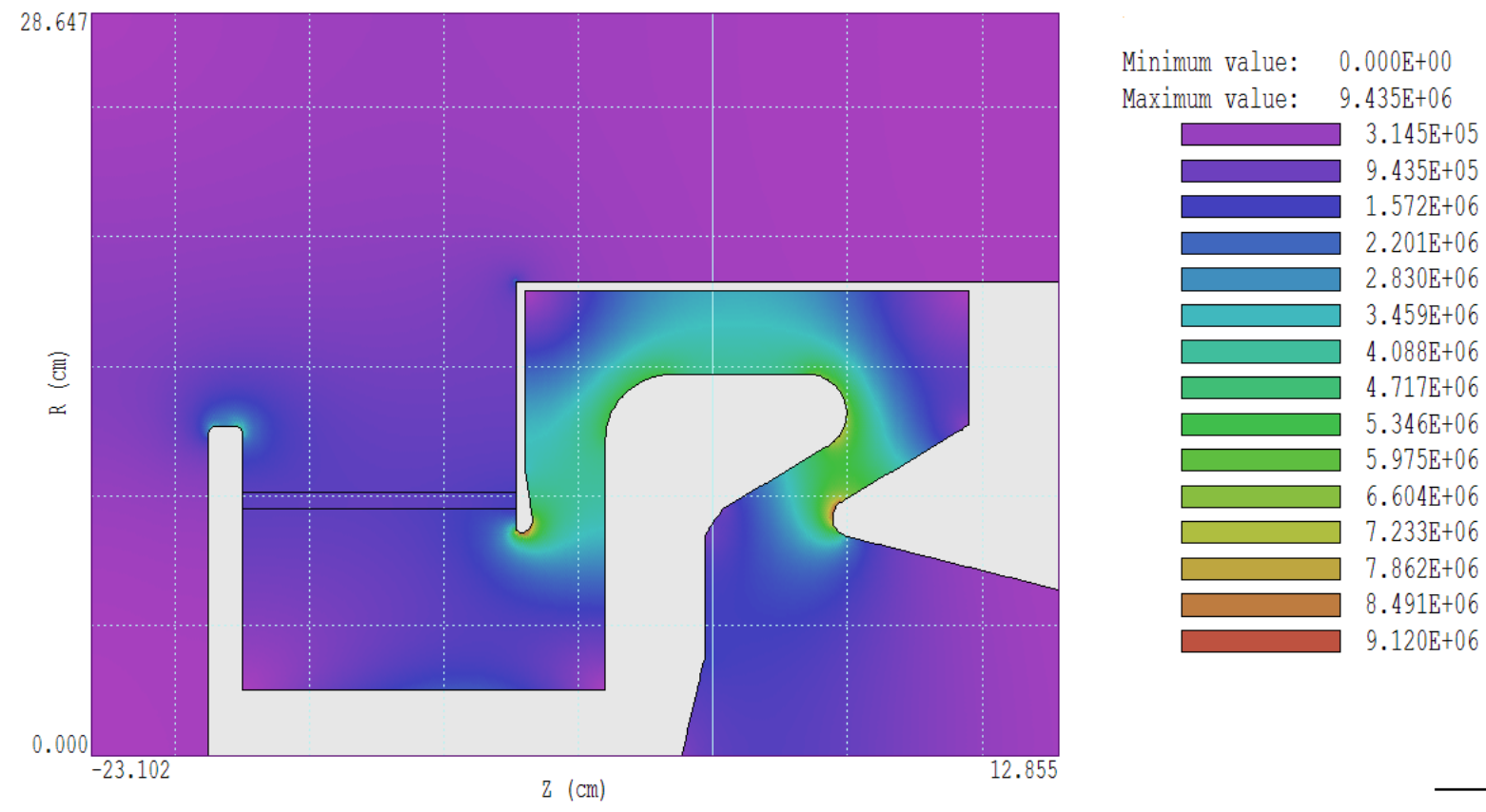

Figure 21. Electric field magnitudes in the electron gun. The maximum field on the focus electrode is 64 $\mathrm{kV} / \mathrm{cm}$. 
Table 4. Electron gun parameters

\begin{tabular}{|l|l|}
\hline Voltage & $120 \mathrm{kV}$ \\
\hline Current & $140 \mathrm{~A}$ \\
\hline Drift tube radius & $4.0 \mathrm{~cm}$. \\
\hline Outer Beam Radius & $3.6 \mathrm{~cm}$ \\
\hline Inner Beam Radius & $3.2 \mathrm{~cm}$ \\
\hline Beam Current Density & $\begin{array}{l}16.4 \\
\mathrm{~A} / \mathrm{cm}^{2}\end{array}$ \\
\hline Beam Ripple & $2 \%$ \\
\hline $\begin{array}{l}\text { Cathode Current } \\
\text { Density }\end{array}$ & $1.9 \mathrm{~A} / \mathrm{cm}^{2}$ \\
\hline $\begin{array}{l}\text { Magnetic Focusing } \\
\text { Field }\end{array}$ & $2 \mathrm{kG}$ \\
\hline
\end{tabular}

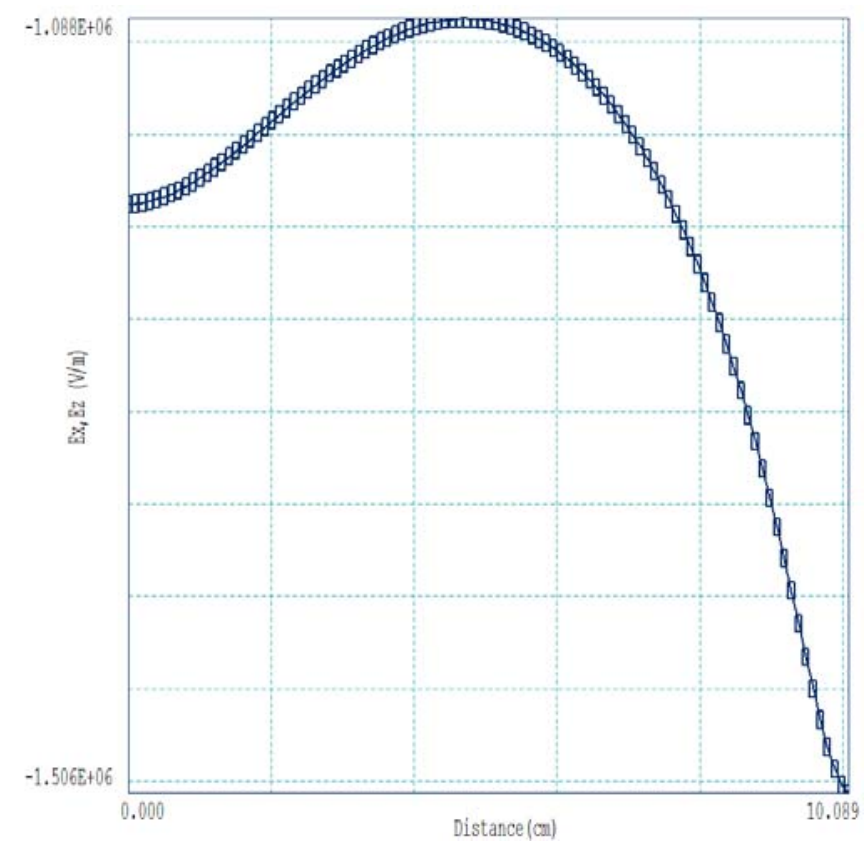

Figure 22. Electric field on vacuum side of HV ceramic

The field along the vacuum side of the high voltage insulator is shown in Figure 22. The field is less than $15 \mathrm{kV} / \mathrm{cm}$, well within acceptable levels.

\section{Task (3): Design of other components, including the collector, input and output couplers, output window, and the magnetic circuit}

\section{Collector}

The collector, shown in Figure 23, was designed using the 2D code TRAK. The peak power density is shown in Figure 24. At the point of maximum power density, the temperature will rise approximately $13^{\circ} \mathrm{C}$ during the $1.5 \mathrm{~ms}$ pulse. This is within acceptable levels.

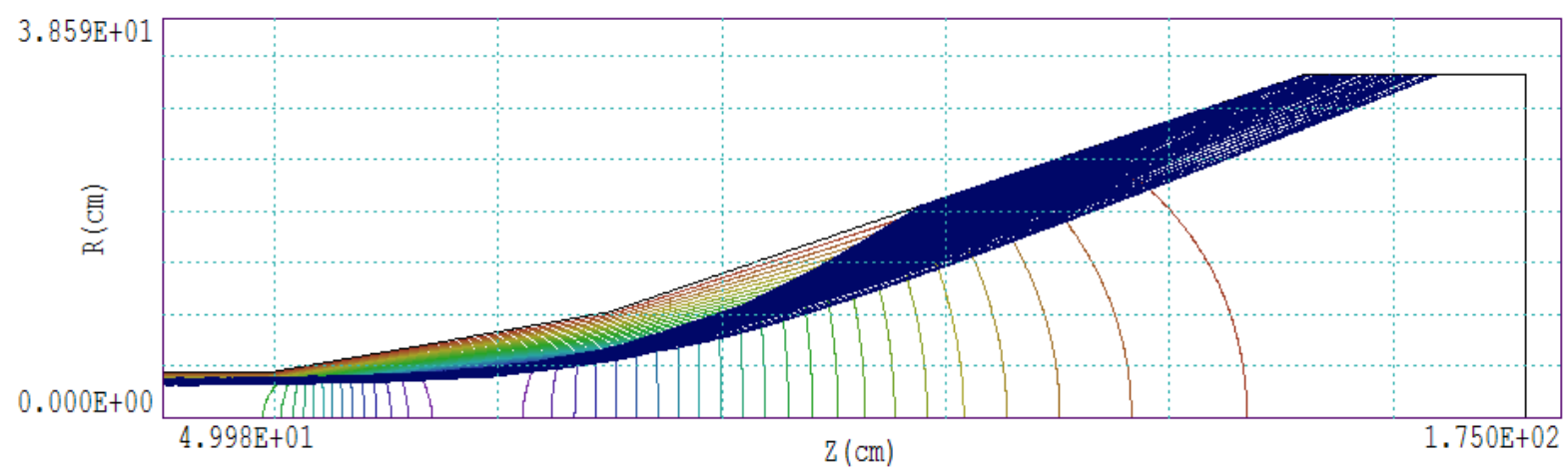

Figure 23. Collector for the $200 \mathrm{MW}$ ABK, showing trajectories with RF. 


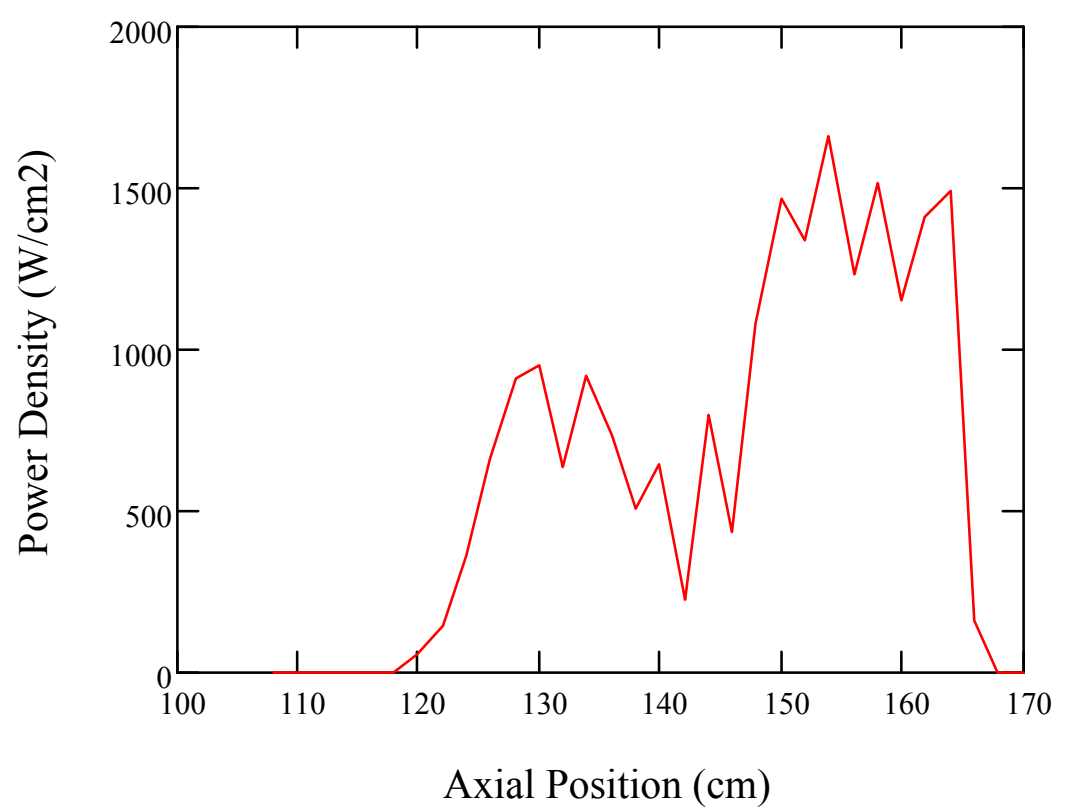

Figure 24. Power density for the collector shown in Figure 23.

With a pulse repetition rate of $10 \mathrm{~Hz}$, the maximum average power density will be about 23 $\mathrm{W} / \mathrm{cm}^{2}$, which is easily cooled with water. Results of a thermal analysis of the collector, using ANSYS, are shown in Figure 25.

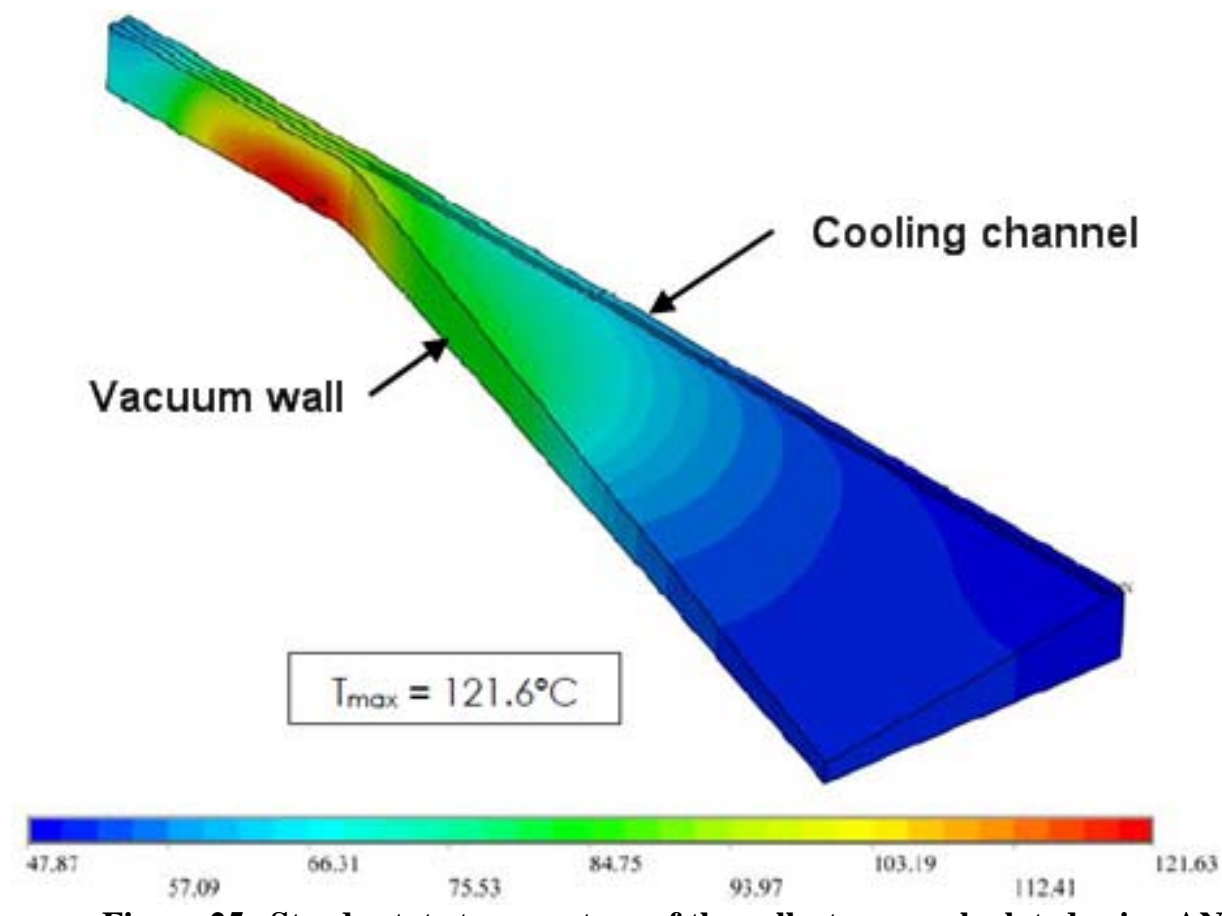

Figure 25. Steady state temperature of the collector, as calculated using ANSYS. 


\section{Magnetic Circuit}

Solenoid focusing employs a configuration typical of large klystrons. A solid model and the magnetic field profile are shown in Figure 26 and Figure 27, respectively. A small coil (not shown) will provide shaping of the field at the collector.

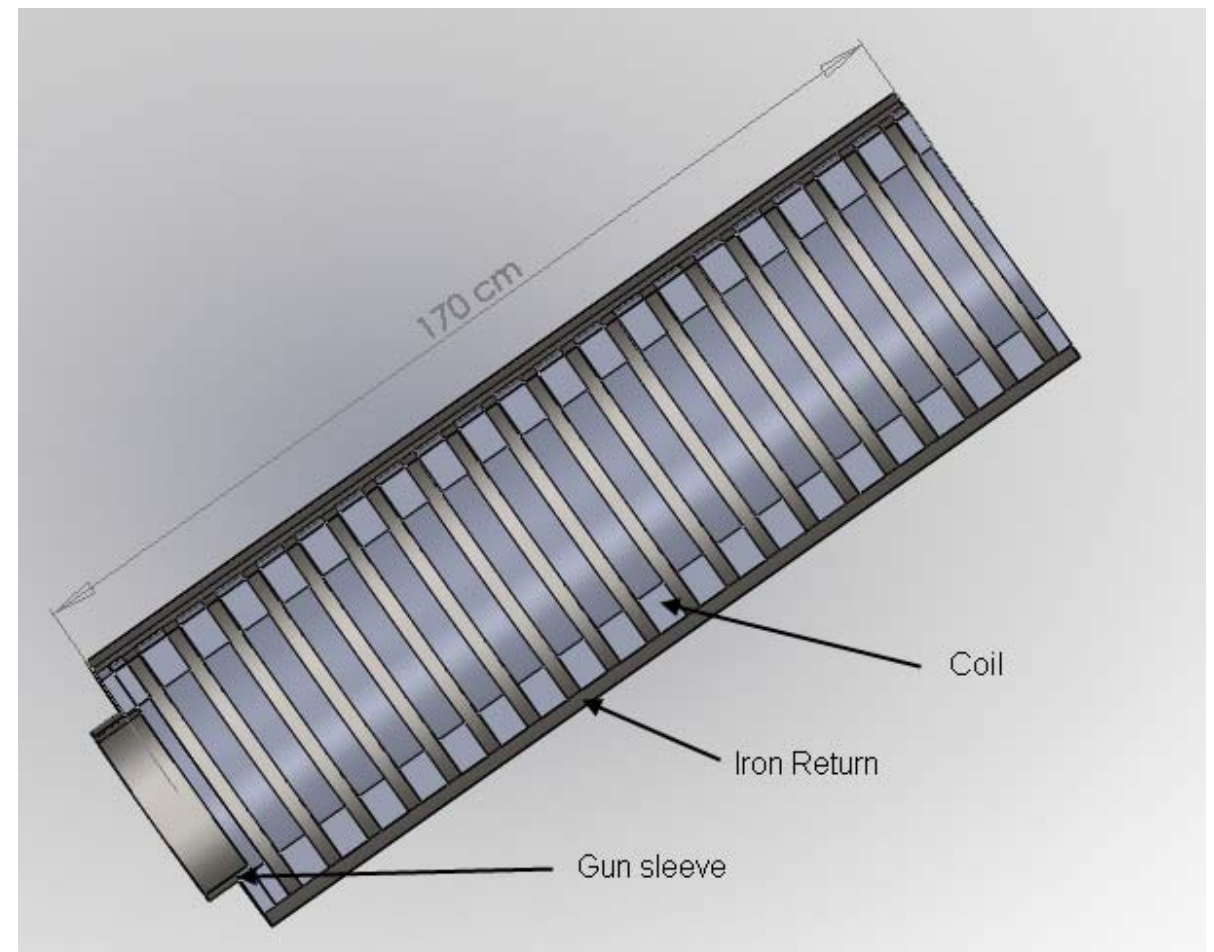

Figure 26. Solid model of the solenoid.

The coil area is consistent with a current density of $300 \mathrm{~A} / \mathrm{cm}^{2}$, a commonly accepted engineering limit. With this current density, the power required to produce the required 2 $\mathrm{kG}$ will be about $20 \mathrm{~kW}$. This is about $8 \%$ of the average beam power. Increasing the outer diameter of the coils will reduce the magnet power.

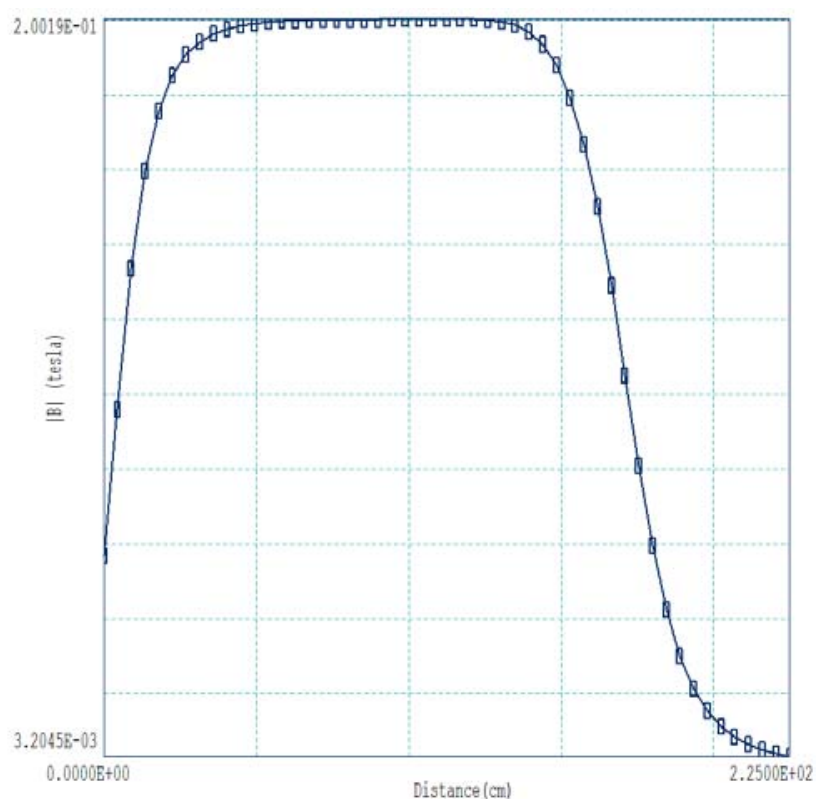

Figure 27. Magnetic field from the solenoid. The peak field is 0.2 Tesla. 


\section{Output cavity and output coupler}

The output coupling uses two waveguide irises $180^{\circ}$ apart. The design must not adversely impact the electric fields at the location of the electron beam, so the cavity cross section is elliptical to compensate for the distortion caused by the iris coupling. Cavity fields were calculated using Ansoft Corporation's High Frequency Structure Simulator (HFSS). The contours of the electric field magnitude with an ellipticity of 0.8 are shown in Figure 28. The magnitude of $E_{z}$ along an arc at the middle of the beam annulus is plotted in Figure 29. The variation of the field is +/$2 \%$, which has a negligible effect on the beam interaction.

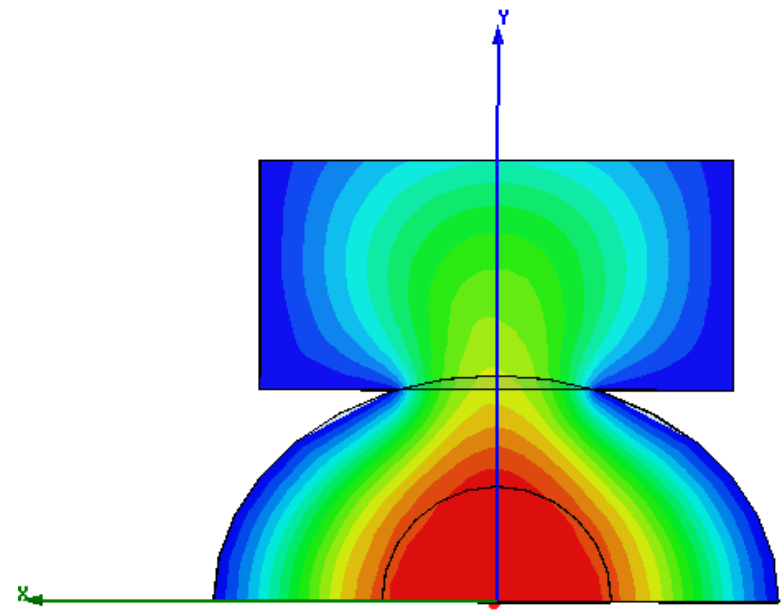

Figure 28. Cross section of $1 / 2$ of the output cavity and output waveguide, showing contours of equal RF electric field.

The external Q of the output cavity is 26 . An HFSS plot of S12 is shown in Figure 30.

\section{Input coupler}

The input coupler will use a loop connected to a coaxial line. This is a simple design that will be finalized in the Phase II program.

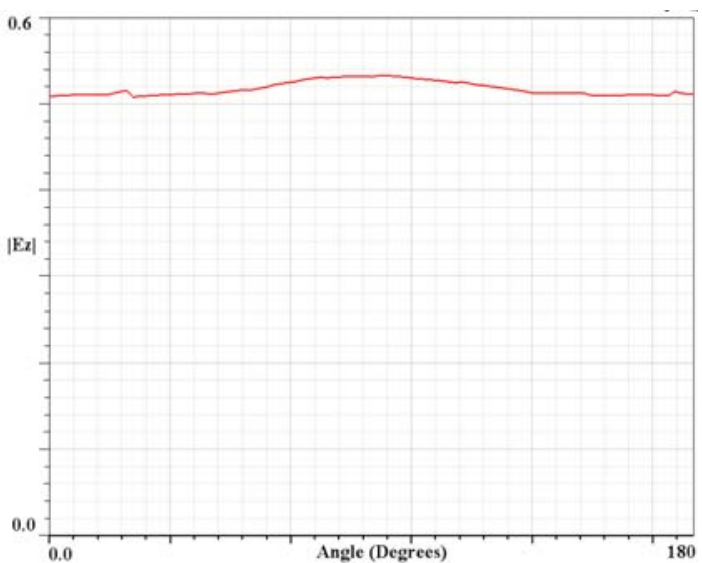

Figure 29. $E_{z}$ along an arc in the $x y$ plane at $\mathrm{r}=3.4 \mathrm{~cm}$ (middle of the beam).

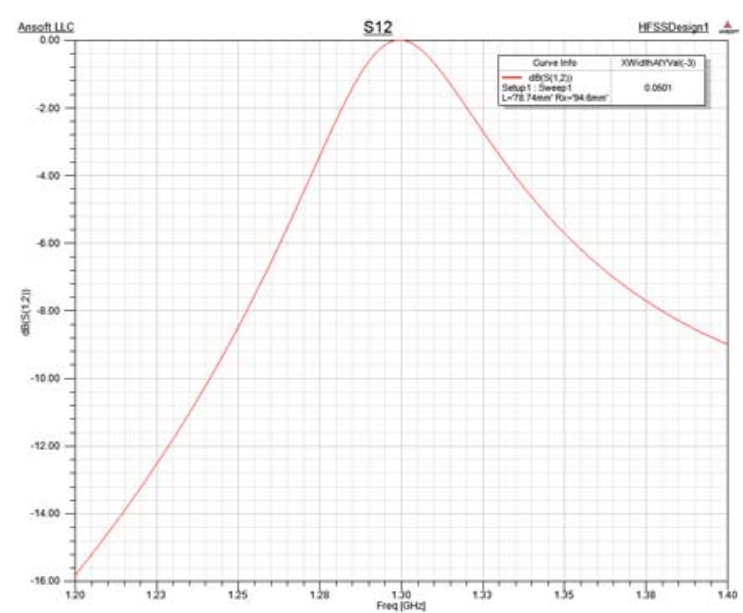

Figure 30. Plot of S12 for the output cavity. 


\section{Output window}

The klystron will use two pillbox output windows (Figure 31). The windows were designed using CASCADE, and a plot of the voltage standing wave ratio (VSWR) is shown in Figure 32.

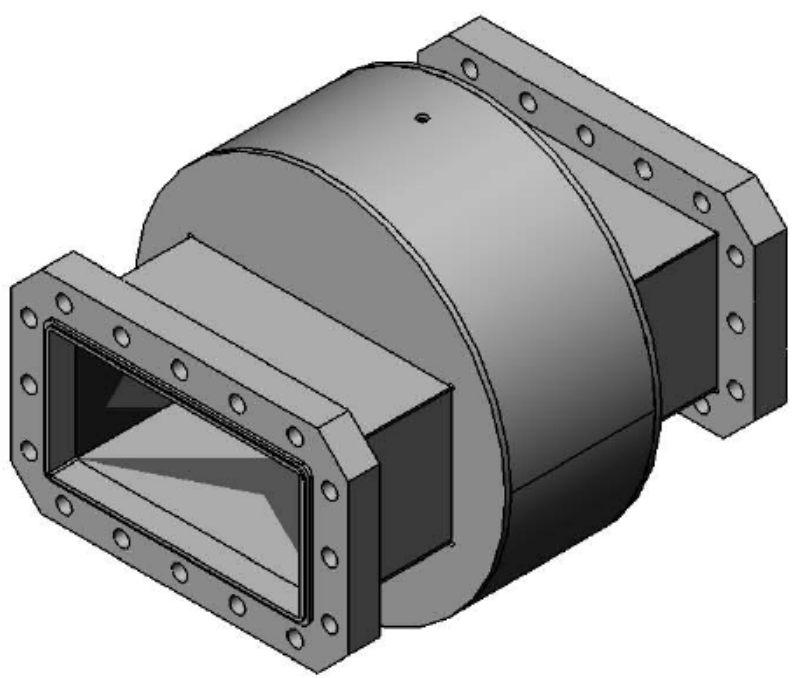

Figure 31. Solid model of the $1.3 \mathrm{GHz}$ output window. The window diameter is $23.3 \mathrm{~cm}$.

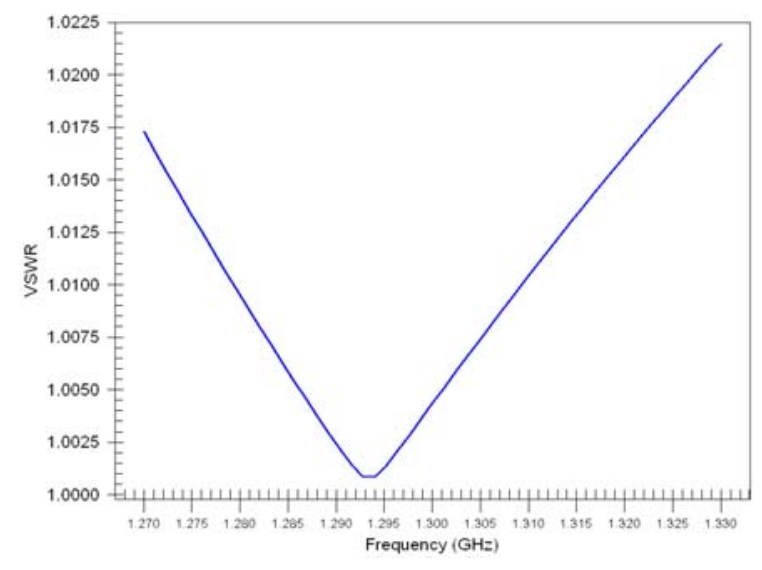

Figure 32. VSWR versus frequency for the output window.

Figure 33 shows a photograph of one of two windows fabricated for CCR's $200 \mathrm{MW}, 1.3 \mathrm{GHz}$ ABK. The measured VSWR was1.095:1, as shown in Figure 34. This satisfied the specification for a VSWR less than 1.2:1.

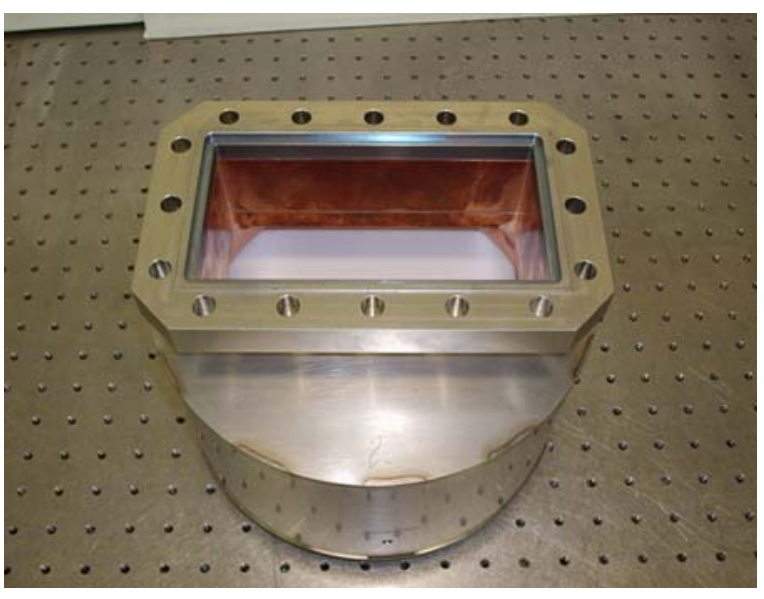

Figure 33. L-Band window for the ABK. This was fabricated in a previous DOE SBIR.

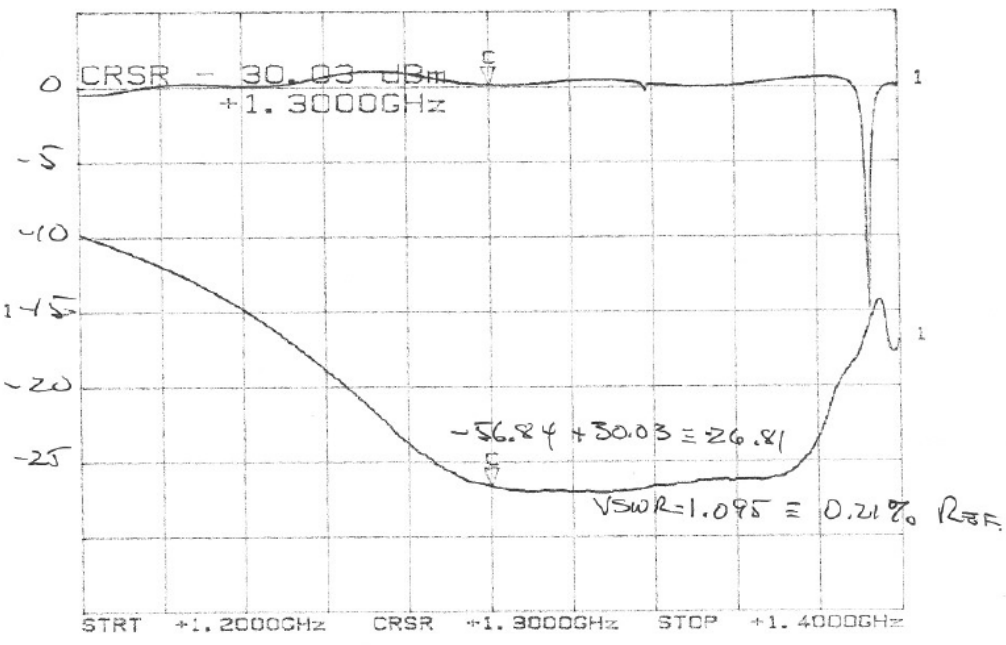

Figure 34. S11 for output window \#1. 


\section{Task (4): Preparation of a preliminary mechanical layout}

Figure 35. Solid model of the ABK.shows the preliminary solid model with and without the solenoid. The tube is approximately $9.5 \mathrm{ft}$ long, and the diameter of the solenoid is 22 inches. The collector diameter is approximately 28 inches.
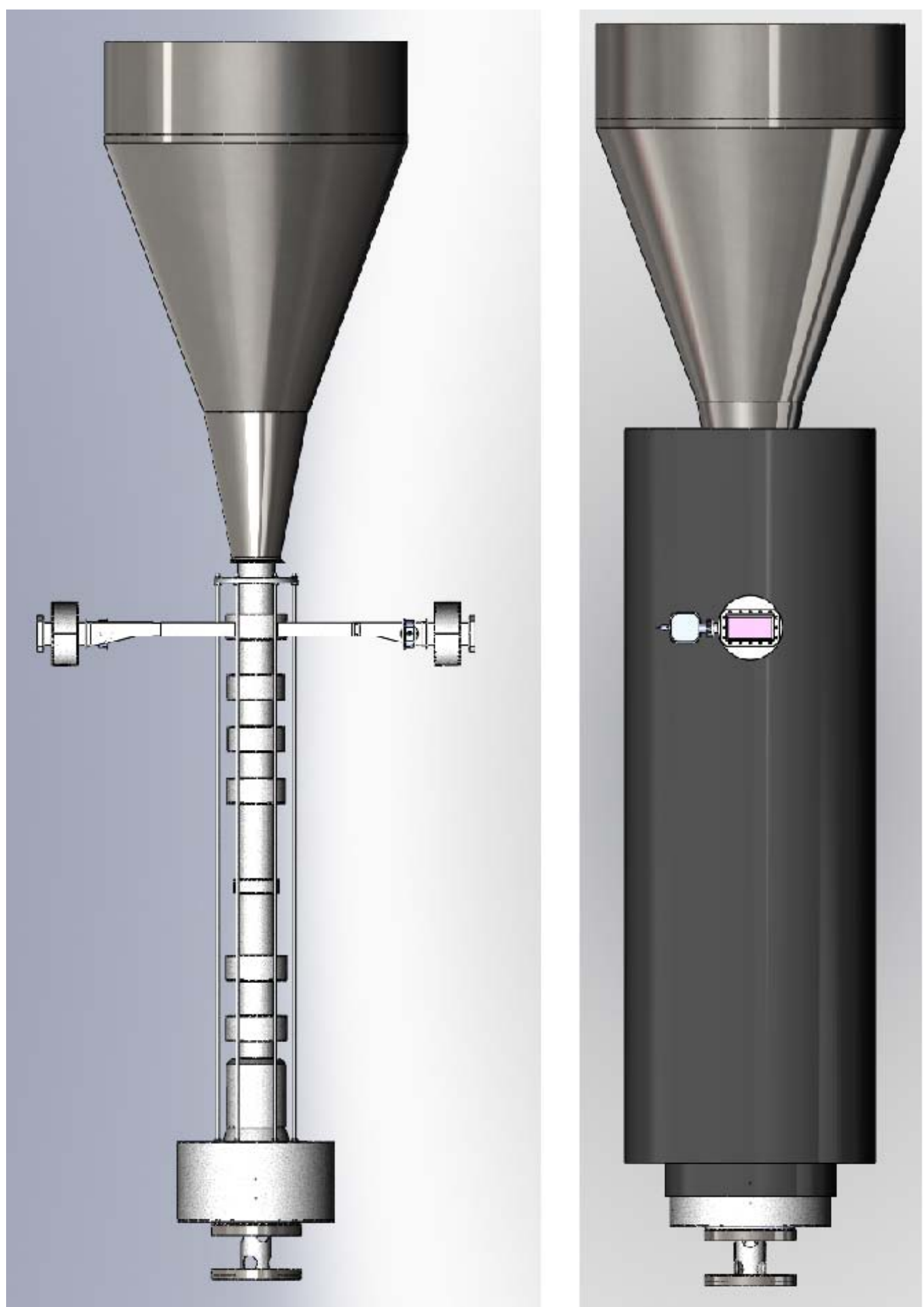

Figure 35. Solid model of the ABK. 


\section{Summary}

The Phase I program achieved all the goals and clearly demonstrated feasibility of an annular beam klystron for the ILC and similar accelerator systems. The design utilizes a single cathode and beam tunnel with simple, fundamental mode cavities. Consequently, the device offers a much lower cost option for driving accelerator cavities than multiple beam or sheet beam klystrons.

The next stage in the development will include optimizing the performance to increase the efficiency above $65 \%$ and investigating options for reducing the size of the collector. This will be followed by fabrication and test of a prototype klystron. 


\section{References}

1. ILC Klystron Design Options and Klystron Manufacturing, www.slac.stanford.edu/econf/C0508141/proc/pres/ILCAW0212_TALK.PDF

2. B.E. Carlsten, "Large-signal klystron simulations using KLSC," Proc. 1997 Particle Accelerator Conference, pp. 3129-3131 (1997).

3. A. N. Vlasov, T. M. Antonsen, D. P. Chernin, B. Levush, and E. L.Wright, "Simulation of microwave devices with external cavities using MAGY," IEEE Trans. Plasma Sci., vol. 30, pp. 1277-1291, June 2002.

4. B. Goplen, L. Ludeking, D. Smithe and G. Warren, "User Configurable Magic Code for Electromagnetic PIC Calculations," Computational Physics Communication, Vol 27, pp. 54 (1995).

5. Igor Chernyaskiy, personal communication (2010).

6. High Voltage Vacuum Insulation, R. Latham, editor, Academic Press, London, p. 427 (1995). 
